\title{
Molecular screening for bacterial pathogens in ticks (Ixodes ricinus) collected on migratory birds captured in northern Italy
}

\author{
Massimo Pajoro ${ }^{1}$, Dario Pistone ${ }^{2,3}$, Ilaria Varotto Boccazzi ${ }^{3}$, Valeria Mereghetti ${ }^{4}$, Claudio Bandi ${ }^{1,3}$, \\ Massimo Fabbi ${ }^{5}$, Francesco Scattorin ${ }^{3}$, Davide Sassera $^{6}$ and Matteo Montagna ${ }^{4}$ \\ ${ }^{1}$ Pediatric Clinical Research Center Romeo ed Enrica Invernizzi, University of Milano, Italy; \\ ${ }^{2}$ University of South Bohemia, Faculty of Science, České Budějovice, Czech Republic; \\ ${ }^{3}$ Department of Bioscience, University of Milano, Italy; \\ ${ }^{4}$ Department of Agricultural and Environmental Sciences, University of Milano, Italy; \\ ${ }^{5}$ Istituto Zooprofilattico Sperimentale della Lombardia e dell'Emila Romagna, Pavia, Italy; \\ ${ }^{6}$ Department of Biology and Biotechnology, University of Pavia, Italy
}

\begin{abstract}
Migratory birds have an important role in transporting ticks and associated tick-borne pathogens over long distances. In this study, 2,793 migratory birds were captured by nets in a ringing station, located in northern Italy, and checked for the presence of ticks. Two-hundred and fifty-one ticks were identified as nymphs and larvae of Ixodes ricinus (Linnaeus, 1758) and they were PCR-screened for the presence of bacteria belonging to Borrelia burgdorferi sensu lato, Rickettsia spp., Francisella tularensis and Coxiella burnetii. Four species of Borrelia (B. garinii, B. afzelii, B. valaisiana and B. lusitaniae) and three species of Rickettsia (R. monacensis, R. helvetica and Candidatus Rickettsia mendelii) were detected in $74(30 \%)$ and $25(10 \%)$ respectively out of 251 ticks examined. Co-infection with Borrelia spp. and Rickettsia spp. in the same tick sample was encountered in 7 (7\%) out of the 99 infected ticks. We report for the first time the presence of Candidatus Rickettsia mendelii in I. ricinus collected on birds in Italy. This study, besides confirming the role of birds in dispersal of I. ricinus, highlights an important route by which tick-borne pathogens might spread across different countries and from natural environments towards urbanised areas.
\end{abstract}

Keywords: Migratory birds, tick-borne pathogens, Borrelia spp., Candidatus Rickettsia mendelii, molecular characterisation

Migratory birds can carry ticks and associated tickborne pathogens (TBPs) over long distances (e.g. Elvfing et al. 2010, Lindeborg et al. 2012, Paduraru et al. 2012). In addition, many avian species can be reservoirs of several TBPs (Gryczyńska and Welc-Falęciak 2016). The spread of ticks across geographical barriers was confirmed by molecular studies that found rather homogeneous genetic structure of tick populations (Porretta et al. 2013, Røed et al. 2016). This finding could be explained by the movement of tick hosts such as migratory birds and mammals across different environments (Galdikaite et al. 2013, Porretta et al. 2013).

Over recent decades, climate and environmental changes have contributed to the range expansion of some tick species, e.g. Ixodes ricinus (Linnaeus, 1758), to northern latitudes and to higher altitudes (Dantas-Torres 2015). Ticks and related TBPs are also rapidly expanding from wild and natural areas to urban and peri-urban zones increasing human health risk (Corrain et al. 2012, Rizzo- li et al. 2014, Biernat et al. 2014, Mehlhorn et al. 2015, Paul et al. 2016, Hansford et al. 2017).

For example, Lyme disease borreliae were detected in host-seeking I. ricinus collected in wild and suburban recreational areas close to Milan (Pistone et al. 2010, Olivieri et al. 2017) and the presence of various TBPs was repoted in birds captured in urban areas of Tuscany (Ebani et al. 2016). These results are in agreement with a global trend, observed not only in the Palearctic region, but also in the Nearctic. As an example, in a suburban area of Chicago (in USA), the presence of Borrelia spp. was reported in different tick species collected on wild birds (Hamer et al. 2012).

The aim of this study was to investigate the presence of four groups of important zoonosis-causing bacterial agents (Rickettsia spp., Borrelia burgdorferi sensu lato, Francisella tularensis and Coxiella burnetii) in I. ricinus collected from migratory birds captured at the border of a highly urbanised and interconnected area in northern Italy.

Address for correspondence: Matteo Montagna, Department of Agricultural and Environmental Sciences, Università degli Studi di Milano, Via Celoria 2, 20133 Milano, Italy, Phone +390250316782 E-mail: matteo.montagna@unimi.it 


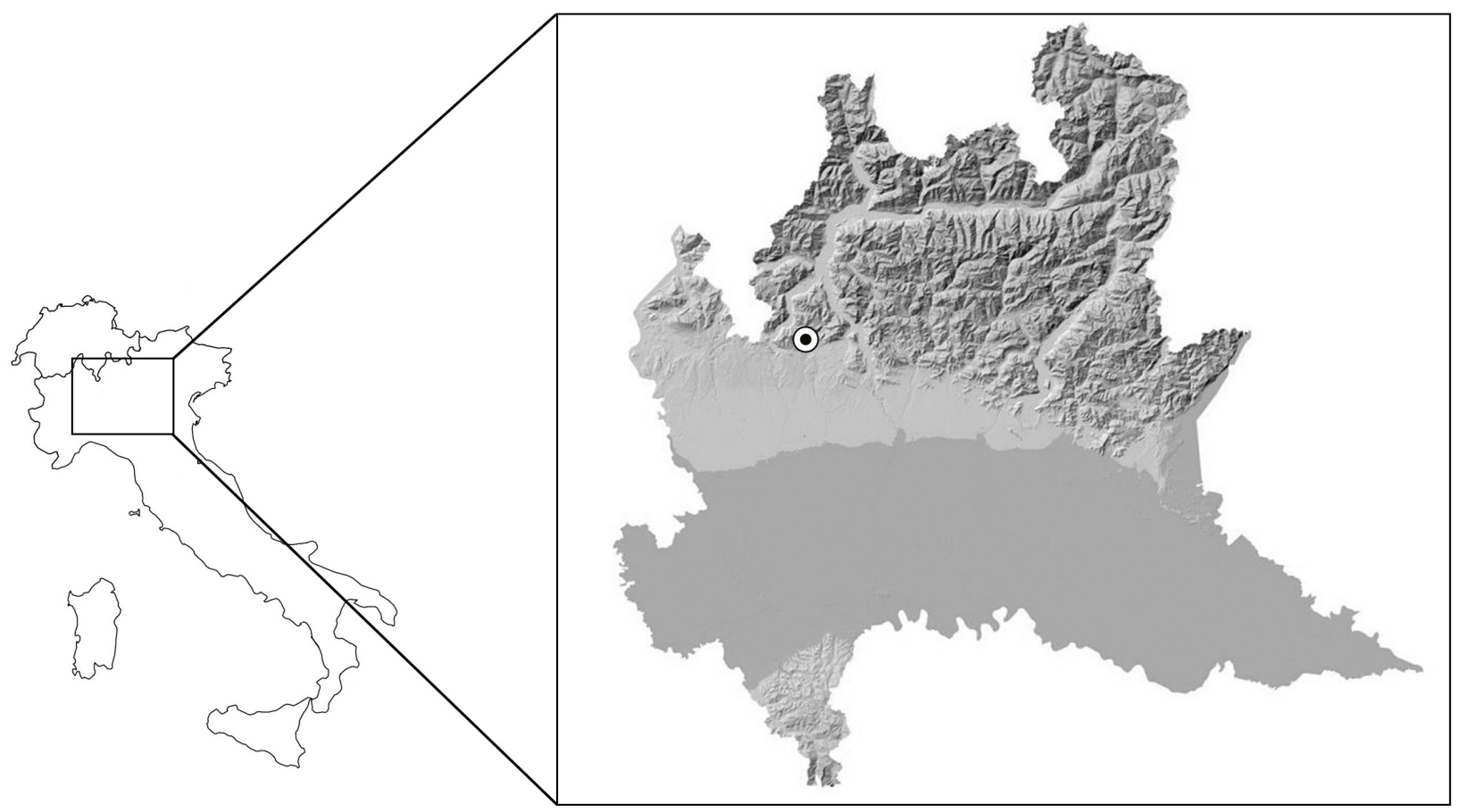

Fig. 1. Geographical location of the bird ringing station Fondazione Europea il Nibbio, Lombardy, Italy (in a highly urbanised area).

\section{MATERIALS AND METHODS}

\section{Collection and identification of ticks}

Ticks were collected from migratory birds trapped with nets at the ringing station Fondazione Europea il Nibbio-FEIN (Arosio, Como, Italy $45^{\circ} 43^{\prime} 54.87^{\prime \prime} \mathrm{N}, 9^{\circ} 12^{\prime} 40.10^{\prime \prime} \mathrm{E}, 353 \mathrm{~m}$ a.s.1.; Fig. 1) during their autumn migration from central Europe. Our survey was conducted from September $6^{\text {th }}$ to October $29^{\text {th }} 2010$. We followed a strategy adopted in Hornok et al. (2014): infected birds were divided into two categories based on their feeding behaviour, those preferentially feeding at ground level and those feeding on trees and bushes. The tick prevalence was compared between the two different categories of bird species. All visible ticks were removed from each bird, and placed in single vials in absolute ethanol and stored at $-20^{\circ} \mathrm{C}$. Ticks were examined using stereomicroscope (Leica MS5, Microsystems GmbH, Wetzlar, Germany) and identified using standard taxonomic keys (Manilla 1998).

\section{Statistical analysis}

Exact confidence intervals (CIs) for the prevalence rates at the $95 \%$ level were calculated according to Sterne's method (Reiczigel 2003). Sample prevalence data were analysed using Fisher's exact test. Differences were considered statistically significant when $\mathrm{P}<0.05$. All the statistical analyses were performed using the open source environment $\mathrm{R}$ - version 3.4.1 ( $\mathrm{R}$ Core team 2017).

\section{DNA extraction, PCR protocols, sequence data analyses}

For DNA extraction, ticks were washed with sterile, distilled water to remove ethanol. Homogenates were then prepared from each dried sample using sterile pestles. DNA was extracted using a commercial kit (DNeasy ${ }^{\circledR}$ Blood \& Tissue kit, Qiagen) following manufacturer's instructions. Extracted DNAs were then quantified with Nanodrop 1000 (Thermo Scientific, Wilmington, DE, USA). To confirm morphological identifications, all samples were subjected to a PCR protocol amplifying a fragment of gene coding for cytochrome oxidase I subunit (COI) following Lado et al. (2016). A subset of the obtained amplicons was then sequenced (i.e. those obtained from DNAs of morphologically unidentifiable ticks due to partial damage of the body and a random $40 \%$ of the remaining individuals).

All the DNAs that resulted in positive amplifications using PCR primers targeting $C O I$ were examined for the presence of the following zoonotic etiological agents: Borrelia burgdorferi sensu lato, Rickettsia spp., Coxiella burnetii and Francisella tularensis. Molecular screening for B. burgdorferi sensu lato was carried out by PCR targeting the ribosomal 16S rRNA gene (Marconi and Garon 1992). Positive samples were amplified and sequenced using a PCR for the 23S-5S rRNA Internal Transcribed Spacer (ITS) (Chu et al. 2008).

Detection of bacteria belonging to the genus Rickettsia was performed by targeting a fragment of the gene coding for the enzyme citrate synthase ( $g l t A$ ), following Labruna et al. (2004) and a fragment of the gene coding for the outer membrane protein (ompA), following Roux et al. (1996). Specific PCR protocols targeting the transposon-like genome region and a fragment of the 16S rRNA gene were used to test for the presence of $C$. burnetii (see Berri et al. 2000) and F. tularensis (see Forsman et al. 1994), respectively.

All PCR positive samples were bidirectionally sequenced by ABI technology (Applied Biosystems, Foster City, CA, USA). Forward and reverse electropherograms were manually corrected and merged into a consensus sequence using the BioEdit v7.1 sequence alignment editor (http://www.mbio.ncsu.edu/BioEdit/ bioedit.html) and compared with those available in GenBank using BLASTn (www.ncbi.nlm.nih.gov/blast/Blast.cgi). Species assignment was confirmed when the sequence identity was $\geq 99 \%$. 


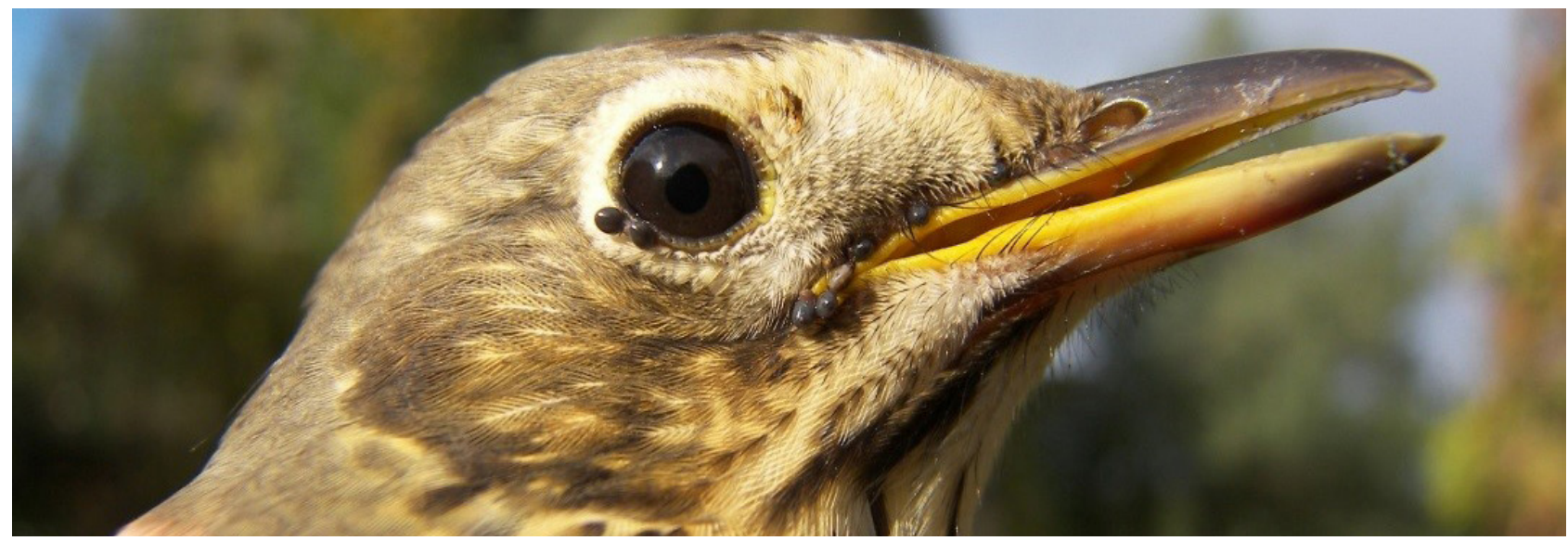

Fig. 2. Song thrush (Turdus philomelos Brehm) parasitised by larvae and nymphs of Ixodes ricinus (Linnaeus, 1758), showing an example of the co-feeding phenomena.

Table 1. Information on the captured birds and their ticks and tick-borne pathogens.

\begin{tabular}{|c|c|c|c|c|c|c|c|}
\hline Bird species (\%) & Feed. pref. $(\%)$ & Dist. migr. (\%) & Ticks & Average & PB & PR & PBR \\
\hline $\begin{array}{l}\text { Anthus trivialis (Linnaeus) } \\
10 / 108(9)\end{array}$ & $\begin{array}{c}\text { GL } 122 / 1713 \\
(7)\end{array}$ & $\begin{array}{c}\text { long } 10 / 108 \\
(10)\end{array}$ & $10(2 ; 8)$ & 1.0 & 0 & 0 & 0 \\
\hline $\begin{array}{l}\text { Erithacus rubecula (Linnaeus) } \\
16 / 472(3)\end{array}$ & & $\begin{array}{c}\text { Short } 112 / 1605 \\
(7)\end{array}$ & $23(13 ; 10)$ & 1.4 & 0 & $2(2 ; 0)[9 \%]$ & 0 \\
\hline $\begin{array}{l}\text { Fringilla coelebs Linnaeus } \\
5 / 249(2)\end{array}$ & & & $6(3 ; 3)$ & 1.2 & 0 & $1(0 ; 1)[17 \%]$ & 0 \\
\hline $\begin{array}{l}\text { Parus major Linnaeus } \\
\text { 3/99 (3) }\end{array}$ & & & $3(1 ; 2)$ & 1.0 & $1(1 ; 0)[33 \%]$ & 0 & 0 \\
\hline $\begin{array}{l}\text { Turdus iliacus Linnaeus } \\
8 / 20(40)\end{array}$ & & & $41(14 ; 27)$ & 5.1 & $\begin{array}{c}8(1 ; 7) \\
{[2 \% ; 17 \%]}\end{array}$ & $5(0 ; 5)[12 \%]$ & $(0 ; 1)$ \\
\hline $\begin{array}{l}\text { Turdus merula Linnaeus } \\
1 / 71(1)\end{array}$ & & & $6(4 ; 2)$ & 6.0 & 0 & $1(1 ; 0)[17 \%]$ & 0 \\
\hline $\begin{array}{l}\text { Turdus philomelos Brehm } \\
79 / 694 \text { (11) }\end{array}$ & & & $183(56 ; 127)$ & 2.3 & $\begin{array}{l}64(8 ; 56) \\
{[4 \% ; 31 \%]}\end{array}$ & $\begin{array}{l}16(4 ; 12) \\
{[2 \% ; 7 \%]}\end{array}$ & $(1 ; 5)$ \\
\hline $\begin{array}{l}\text { Sylvia atricapilla (Linnaeus) } \\
1 / 442(0.2)\end{array}$ & $\begin{array}{l}\text { AGL } 2 / 517 \\
\quad(0.4)\end{array}$ & $\begin{array}{l}\text { Middle } 1 / 442 \\
(2)\end{array}$ & $1(1 ; 0)$ & 1.0 & 0 & 0 & 0 \\
\hline $\begin{array}{l}\text { Coccothraustes coccothraustes } \\
\text { (Linnaeus) } 1 / 75(1)\end{array}$ & & Short 1/75 (1) & $1(0 ; 1)$ & 1.0 & $1(0 ; 1)[100 \%]$ & 0 & 0 \\
\hline
\end{tabular}

For every bird species is reported the ratio between the parasitised birds and the total number of screened birds ( 2,230 individuals belonging to the nine reported species), in brackets is reported the values expressed as percentages. GL - ground level; ABL -above ground level; TICKS - total number of collected ticks: in brackets are the values expressed for larva (first value) and nymph (second value) stages; AVERAGE - average number of ticks collected for each infected bird; PB - number of ticks infected with Borrelia spp.; within brackets are positive larvae and nymphs, in square brackets the percentage of prevalence; PR - number of ticks infected with Rickettsia spp; within brackets are positive larvae and nymphs, in square brackets the percentage of prevalence; PBR - number of ticks simultaneously infected with both pathogens.

\section{RESULTS}

During the sampling campaign, 2,793 birds belonging to 41 different species were captured and checked for the presence of ticks (Fig. 2). A total of 274 ticks were collected from 124 birds, belonging to nine different species: Turdus philomelos Brehm, Turdus merula Linnaeus, Turdus iliacus Linnaeus, Erithacus rubecula (Linnaeus), Sylvia atricapilla (Linnaeus), Parus major Linnaeus, Fringilla coelebs Linnaeus, Anthus trivialis (Linnaeus), Coccothraustes coccothraustes (Linnaeus).

Statistical analysis showed that birds preferentially feeding at ground level were more frequently infected by ticks than those preferentially feeding above ground level ( $\mathrm{P}<0.0001)$, with 122 out of 1713 (7\% [CI: 6-8\%]) and 2 out of 517 (0.4\% [CI: $0.04-1 \%])$ parasitised individuals, respectively. Of the 274 individual ticks, 94 were at the larval stage (34.3\%) and 180 nymphs (65.7\%). COI amplicons were obtained for 251 DNAs from the total 274 DNA samples (88/94 larvae and 163/180 nymphs). BLASTn analyses on all the sequenced $C O I$ amplicons confirmed the morphological identification of the specimens $(100 \%$ identity with I. ricinus). Pathogens screening was conducted on DNAs extracted from 88 larvae and 163 nymphs.

PCR positivity to Borrelia spp. was detected in 10 out of 88 larvae (11\%) and 64 out of 163 nymphs $(39 \%)$ and bacteria belonging to the genus Rickettsia were detected in 7 out of 88 larvae $(8 \%)$ and 18 out of 163 nymphs $(11 \%)$. Co-infection with both pathogens was encountered in 7 out of 99 (7.1\%) infected ticks. Francisella tularensis and C. burnetii were not detected in any samples. (Table 1).

Four different genospecies of Borrelia spp. were identified: Borrelia garinii (19.5\%), Borrelia afzelii $(4.8 \%)$, Borrelia valaisiana (2.4\%) and Borrelia lusitaniae ( $0.4 \%)$. Six amplicons did not produce high quality sequences, perhaps due to the presence of multiple strains or genospecies, impeding identification at species level (Table 2). The 
Table 2. Borrelia spp. and Rickettsia spp. genotypes detected from Ixodes ricinus (Linnaeus, 1758) collected on migratory birds.

\begin{tabular}{lccc}
\hline Species & $\begin{array}{c}\mathrm{N}^{\circ} \\
\text { sequences }\end{array}$ & Genomic region & GeneBank acc. No. \\
\hline B. afzelii & 3 & ITS & LT907801 \\
B. afzelii & 4 & ITS & LT907802 \\
B. afzelii & 1 & ITS & LT907803 \\
B. afzelii & 4 & ITS & LT907804 \\
B. garinii & 12 & ITS & LT907805 \\
B. garinii & 8 & ITS & LT907806 \\
B. garinii & 9 & ITS & LT907807 \\
B. garinii & 3 & ITS & LT907808 \\
B. garinii & 11 & ITS & LT907809 \\
B. garinii & 6 & ITS & LT907810 \\
B. lusitaniae & 1 & ITS & LT907811 \\
B. valaisiana & 6 & ITS & LT907812 \\
R. helvetica & 5 & gltA gene part. seq. & LT907813 \\
R. mendelii & 3 & gltA gene part. seq & LT907814 \\
R. monacensis & 14 & gltA gene part. seq & LT964677 \\
R. monacensis & 16 & OmpA gene part. seq & LT907815 \\
Rickettsia sp.IRS3 & 3 & OmpA gene part. seq & LT964678 \\
\hline
\end{tabular}

22 electropherograms of $g l t$ A nucleotide sequences, after BLASTn search, allowed to identify Rickettsia monacensis (14 nucleotide sequences), Rickettsia helvetica (5 nucleotide sequences) and three sequences assigned to Candidatus Rickettsia mendelii. The remaining three electropherograms showed multiple double-peaks and therefore were not resolved in consensus sequences. Concerning the second marker, targeting a fragment of ompA gene, 20 amplicons were obtained and allowed to identify $R$. monacensis (16 nucleotide sequences) and a second haplotype (LT964678) with 100\% identity with Rickettsia sp. IRS3 (three nucleotide sequences). Electropherograms of the remaining amplicon did not produce a high-quality consensus sequence. Furthermore, five DNAs of the tick samples positive to $R$. helvetica using primers targeting gltA were not amplified using primers targeting ompA. Notably, it is known that the primers used do not amplify the ompA gene for $R$. helvetica (Roux et al. 1996). Therefore, the results obtained using the two primer pairs are congruent. More details including GenBank accession numbers are presented in Tables 1 and 2.

\section{DISCUSSION}

As already highlighted by previous contributions, our study suggests an increasing risk for human health linked to the current dispersion trend of ticks and associated TBPs outside their elective wild-natural environments (Rizzoli et al. 2014, Kowalec et al. 2017). Here, migratory birds were captured by nets, in a woodland zone geographically located $\sim 30 \mathrm{~km}$ north of Milan, one of the most populated and interconnected areas in Europe. Our results, in agreement with a previous study, show that parasitism rate is connected with birds feeding behaviour (Hornok et al. 2014), indicating that birds are more easily infected when they feed at ground level than when feeding on trees and bushes (Table 1). Indeed, the most parasitised individuals belonged to the ground-level feeders Turdus iliacus, T. philomelos and Anthus trivialis (see Michalik et al. 2008).

Due to the different bird species that can serve as tick hosts and the highly variable routes followed by long and short-range migrators, our results are hardly comparable with other European studies (Toma et al. 2014, Wallménius et al. 2014, Klaus et al. 2016). We focused our molecular screening on pathogens in larvae and nymphs of I. ricinus, one of the tick species most commonly feeding on passerine birds in central Europe (Michalik et al. 2008, Biernat 2016, Klaus et al. 2016).

Four genospecies of Lyme-disease-causing borreliae (B. afzelii, B. garinii, B. lusitaniae and B. valaisiana) were detected in ticks collected from birds during autumn migration from Central Europe. Borrelia garinii was the most prevalent genospecies (20\%), as reported in other studies focused on I. ricinus from birds (Michalik et al. 2008, Dubska et al. 2011). B. afzelii, known to be mostly associated with rodents, was found in 12 nymphs (5\%). These findings are in agreement with other surveys in Europe (e.g. Margos et al. 2009).

In addition, we report the presence of $R$. helvetica and R. monacensis, which are well-known to be implicated in the development of human diseases (e.g. Nilsson et al. 1999, Parola et al. 2013, Nilsson et al. 2014). Remarkably, few ticks (three nymphs collected on two individuals of T. iliacus) were positive for Candidatus Rickettsia mendelii, a recently described non-spotted-fever-group rickettsia, previously detected in I. ricinus from the Czech Republic (Hajduskova et al. 2016).

Our results correspond to studies that indicate that birds may have a relevant role as reservoirs of TBPs (Michalik et al. 2008, Hornok et al. 2014). We found spirochetes of B. burgdorferi s.l. in 10 out of 88 larvae (11\%), a relatively high prevalence of the bacterium considering an inefficient transovarial transmission route (Rollend et al. 2013). Therefore, larvae might have acquired spirochetes through ingestion of infected blood of birds (Voordouw 2015) since the co-feeding mechanism was recently demonstrated to be inefficient in the same avian hosts (Heylen et al. 2017).

In conclusion, our work presents further evidence for the role of birds in the dispersal of I. ricinus and pathogens transmitted by this species, emphasising the possibility of introduction or re-introduction of TBPs in non-endemic and highly populated areas.

Acknowledgements. We thank all the laboratory technicians of IZSLER (Pavia), for their kind assistance during molecular analyses. This study was supported by a grant of the Italian Ministry of Health (PRC2008005). All authors are grateful to the staff of the Fondazione Europea il Nibbio for their contribution in samples collection. 


\section{REFERENCES}

Berri M., Laroucau K., Rodolakis A. 2000: The detection of Coxiella burnetii from ovine genital swabs, milk and fecal samples by the use of a single touchdown polymerase chain reaction. Vet. Microbiol. 72: 285-293.

Biernat B., Stańczak J., Michalik J., Sikora B., Cieniuch S. 2016: Rickettsia helvetica and R. monacensis infections in immature Ixodes ricinus ticks derived from sylvatic passerine birds in west-central Poland. Parasitol. Res. 115: 3469-3477.

Chu C.Y., Jiang B.G., Liu W., Zhao Q.M., Wu X.M., Zhang P.H., Zhan L., Yang H., CaO W.C. 2008: Presence of pathogenic Borrelia burgdorferi sensu lato in ticks and rodents in Zhejiang, south-east China. J. Med. Microbiol. 57: 980-985.

Corrain R., Drigo M., Fenati M., Menandro M.L., Mondin A., Pasotto D., Martini M. 2012: Study on ticks and tickborne zoonoses in public parks in Italy. Zoonoses Publ. Hlth. 59: 468-476.

Dantas-Torres F. 2015: Climate change, biodiversity, ticks and tick-borne diseases: the butterfly effect. Int. J. Parasitol. Parasites Wildl. 4: 452-461.

Dubska L., Literak I., Kocianova E., Taragelova V., Sverakova V., Sychra O., Hromadko M. 2011: Synanthropic birds influence the distribution of Borrelia species: analysis of Ixodes ricinus ticks feeding on passerine birds. Appl. Environ. Microbiol. 77: 1115-1117.

Ebani V.V., Bertelloni F., Mani P. 2016: Molecular survey on zoonotic tick-borne bacteria and chlamydiae in feral pigeons (Columba livia domestica). Asian Pac. J. Trop. Med. 9: 324-327.

Elfying K., Olsen B., Bergström S., Waldenström J., LunDKvist A., Sıöstedt A., Mejlon H., Nilsson K. 2010: Dissemination of spotted fever rickettsia agents in Europe by migrating birds. PLoS ONE 5: 8572.

Forsman M., SandStröm G., Sjöstedt A. 1994: Analysis of 16S ribosomal DNA sequences of Francisella strains and utilisation for determination of the phylogeny of the genus and for identification of strains by PCR. Int. J. Syst. Bacteriol. 44: 38-46.

Galdikaité E., Banaityté A., Paulauskas A., RadziJevskaJA J., Golovljova I. 2013: Investigation of genetic diversity of Ixodes ricinus based on four microsatellite loci. Biologija 59: 201-212.

Gryczyńska A., Welc-Falęciak R. 2016: Long-term study of the prevalence of Borrelia burgdorferi s.l. infection in ticks (Ixodes ricinus) feeding on blackbirds (Turdus merula) in NE Poland. Exp. Appl. Acarol. 70: 381-394.

Hajduskova E., Literak I., Papousek I., Costa F.B., Novakova M., Labruna M.B., ZdraZilova-Dubska L. 2016: 'Candidatus Rickettsia mendelii', a novel basal group rickettsia detected in Ixodes ricinus ticks in the Czech Republic. Ticks Tick Borne Dis. 7: 482-486.

Hamer S.A., Goldberg T.L., Kitron U.D., Brawn J.D., AnDerson T.K., Loss S.R., Walker E.D., Hamer G.L. 2012: Wild birds and urban ecology of ticks and tick-borne pathogens, Chicago, Illinois, USA, 2005-2010. Emerg. Infect. Dis. 18: 1589-1595.

Hansford K.M., Fonville M., Gillingham E.L., Coipan E.C., Pietzsch M.E., Krawczy A.I., Vaux A.G., Cull B., Sprong H., Medlock J.M. 2017: Ticks and Borrelia in urban and peri-urban green space habitats in a city in southern England. Ticks Tick Borne Dis. 8: 353-361.

Heylen D.J., Sprong H., Krawczyk A., Van Houtte N., Genné D., Gomez-Chamorro A., van Oers K., Voordouw M.J. 2017: Inefficient co-feeding transmission of Borrelia afzelii in two common European songbirds. Sci. Rep. 7: 39596.

Hornok S., Kováts D., Csörgö T., Meli M.L., GöNCZI E., HadNaGY Z., Takács N., Farkas R., Hofmann-Lehmann R. 2014: Birds as potential reservoirs of tick-borne pathogens: first evidence of bacteraemia with Rickettsia helvetica. Parasit. Vectors 7: 128.
Klaus C., Gethmann J., Hoffmann B., Ziegler U., Heller M., BEeR M. 2016: Tick infestation in birds and prevalence of pathogens in ticks collected from different places in Germany. Parasitol. Res. 115: 2729-2740.

Kowalec M., Szewczyk T., Welc-Falęciak R., Siński E., Karbowiak G., Bajer A. 2017: Ticks and the city - are there any differences between city parks and natural forests in terms of tick abundance and prevalence of spirochaetes? Parasit. Vectors 10: 573.

Labruna M.B., McBride J.W., Bouyer D.H., Camargo L.M., Camargo E.P., Walker D.H. 2004: Molecular evidence for spotted fever group Rickettsia species in the tick Amblyomma longirostre in Brazil. J. Med. Entomol. 41: 533-537.

Lado P., Nava S., Labruna M.B., Szabo M.P.J., Durden L.A., Bermudez S., Montagna M., Sánchez Quirós A.C., Beati L. 2016. Amblyomma parvum Aragão, 1908 (Acari: Ixodidae): Phylogeography and systematic considerations. Ticks Tick Borne Dis. 7: 817-827.

Lindeborg M., Barboutis C., Ehrenborg C., Fransson T., Jaenson T.G., Lindgren P.E., Lundkvist A., Nyström F., Salaneck E., Waldenström J., Olsen B. 2012: Migratory birds, ticks, and Crimean-Congo hemorrhagic fever virus. Emerg. Infect. Dis. 18: 2095-2097.

Manilla G. 1998: Acari Ixodida. Fauna d'Italia, Vol. 36. Calderini, Bologna, $280 \mathrm{pp}$.

Marconi R.T., Garon C.F. 1992: Development of polymerase chain reaction primer sets for diagnosis of Lyme disease and for species-specific identification of Lyme disease isolates by 16S rRNA signature nucleotide analysis. J. Clin. Microbiol. 30: 2830-2834.

Margos G., Vollmer S.A., Cornet M., Garnier M., Fingerle V., Wilske B., Bormane A., Vitorino L., Collares-Pereira M., Drancourt M., Kurtenbach K. 2009: A new Borrelia species defined by multilocus sequence analysis of housekeeping genes. Appl. Environ. Microbiol. 75: 5410-5416.

Mehlhorn H., Mehlhorn T., Müller M., Vogt M., Rissland J. 2015. Tick survey for prevalent pathogens in peri-urban recreation sites in Saarland and Rhineland-Palatinate (Germany). Parasitol. Res. 115: 1167-1172.

Michalik J., Wodecka B., Skoracki M., Sikora B., Stańczak J. 2008: Prevalence of avian-associated Borrelia burgdorferi $\mathrm{s} .1$. genospecies in Ixodes ricinus ticks collected from blackbirds (Turdus merula) and song thrushes (T. philomelos). Int. J. Med. Microbiol. 298: 129-138.

Nilsson K., Lindquist O., P̊̊hlson C. 1999: Association of Rickettsia helvetica with chronic perimyocarditis in sudden cardiac death. Lancet. 354: 1169-1173.

Nilsson K., Wallménius K., Hartwig S., Norlander T., PÅHLSON C. 2014: Bell's palsy and sudden deafness associated with Rickettsia spp. infection in Sweden. A retrospective and prospective serological survey including PCR findings. Eur. J. Neurol. 21: 206-214

Olivieri E., Gazzonis A.L., Zanzani S.A., Veronesi F., ManFREDI M.T. 2017: Seasonal dynamics of adult Dermacentor reticulatus in a peri-urban park in southern Europe. Ticks Tick Borne Dis. 8: 772-779.

Paduraru O.A., Buffet J.P., Cote M., Bonnet S., Moutailler S., Paduraru V., Femenia F., Eloit M., Savuta G., VAYSSIER-TAUSSAT M. 2012: Zoonotic transmission of pathogens by Ixodes ricinus ticks, Romania. Emerg. Infect. Dis. 18: 2089-2090.

Parola P., Paddock C.D., Socolovschi C., Labruna M.B., Mediannikov O., Kernif T., AbDad M.Y., Stenos J., Bitam I., Fournier P.E., RAOult D. 2013: Update on tick-borne rickettsioses around the world: a geographic approach. Clin. Microbiol. Rev. 26: 657-702. 
Paul R.E.L., Cote M., Le Naour E., Bonnet S.I. 2016: Environmental factors influencing tick densities over seven years in a French suburban forest. Parasite. Vector. 9: 309.

Pistone D., Pajoro M., Fabbi M., Vicari N., Marone P., Genchi C., Novati S., Sassera S., Epis S., Bandi C. 2010: Lyme Borreliosis, Po River Valley, Italy. Emerg. Infect. Dis. 16: 1289-1291.

Porretta D., Mastrantonio V., Mona S., Epis S., Montagna M., Sassera D., Bandi C., Urbanelli S. 2013: The integration of multiple independent data reveals an unusual response to Pleistocene climatic changes in the hard tick Ixodes ricinus. Mol. Ecol. 22: 1666-1682.

R CORE TEAm. 2017: R: A language and environment for statistical computing. R Foundation for Statistical computing, Vienna, Austria, www.r-project.org.

Reiczigel J. 2003: Confidence intervals for the binomial parameter: some new considerations. Stat. Med. 22: 611-621.

Rizzoli A., Silaghi C., Obiegala A., Rudolf I., Hubálek Z., Földvári G., Plantard O., Vayssier-Taussat M., Bonnet S., ŠPitalská E., Kazimírová M. 2014: Ixodes ricinus and its transmitted pathogens in urban and peri-urban areas in Europe: new hazards and relevance for public health. Front. Publ. Hlth. 2: 251 .

Rollend L., Fish D., Childs J.E. 2013: Transovarial transmission of Borrelia spirochetes by Ixodes scapularis: a summary of the literature and recent observations. Ticks Tick Borne Dis. 4: $46-51$.

Roux V., Fournier P.E., Raoult D. 1996: Differentiation of spotted fever group rickettsiae by sequencing and analysis of restriction fragment length polymorphism of PCR-amplified DNA of the gene encoding the protein rOmpA. J. Clin. Microbiol. 34: $2058-2065$.

Røed K.H., Kvie K.S., Hasle G., Gilbert L., Leinaas H.P. 2016: Phylogenetic lineages and postglacial dispersal dynamics characterise the genetic structure of the tick, Ixodes ricinus, in Northwest Europe. PLoS ONE. 11: 0167450.

Toma L., Mancini F., Di Luca M., Cecere J.G., Bianchi R., Khoury C., Quarchioni E., Manzia F., Rezza G., Ciervo A. 2014: Detection of microbial agents in ticks collected from migratory birds in central Italy. Vector Borne Zoonotic Dis. 14: 199-205.

Voordouw M.J. 2015: Co-feeding transmission in Lyme disease pathogens. Parasitology 142: 290-302.

Wallménius K., Barboutis C., Fransson T., Jaenson T.G., Lindgren P.E., Nyström F., Olsen B., Salaneck E., NilsSON K. 2014: Spotted fever Rickettsia species in Hyalomma and Ixodes ticks infesting migratory birds in the European Mediterranean area. Parasit. Vectors. 7: 318.

Cite this article as: Pajoro M., Pistone D., Boccazzi I.V., Mereghetti V., Bandi C., Fabbi M., Scattorin F., Sassera D. and Montagna M. 2018: Molecular screening for bacterial pathogens in ticks (Ixodes ricinus) collected on migratory birds captured in Northern Italy. Folia Parasitol. 65: 008. 